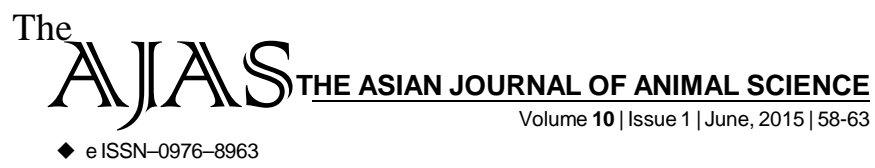

\title{
Influence of different risk factors on the prevalence of fasciolosis in indigenous cattle reared by the nomads near Bhubaneswar, Odisha
}

GAUTAM MAHALIK

AUTHOR FOR CORRESPONDING :

GAUTAM MAHALIK

Department of Veterinary

Parasitology, College of

Veterinary Science and Animal

Husbandry, BHUBANESWAR

(ODISHA) INDIA

Email: gautamm99@gmail.com

\begin{abstract}
A cross sectional study was carried out from August, 2011 to January, 2012 to study the influence of different risk factors on the prevalence of fasciolosis in indigenous cattle reared by the nomads near Bhubaneswar, Odisha. Out of 307 faecal sample examined, only 13 smaples were found positive for Fasciola spp. eggs giving an overall prevalence of 4.23 per cent. Season had significant influence $(\mathrm{P}<0.02)$ on the infection rate with high incidence rate observed in rainy season as compared to winter periods. More infection was found in animals having poor body condition as comapred to that having good health $(\mathrm{P}<0.02)$. The disease was more frequently observed in older animals ( $>2$ years) as compared to young ones $(<2$ years $)(\mathrm{P}<0.05)$. No significant difference $(\mathrm{P}>0.05)$ was noticed in sexwise distribution of the disease.
\end{abstract}

KEY WORDS....... Risk factors, Prevalence, Fasciolosis, Cattle, Nomads, Bhubaneswar

HOW TO CITE THIS ARTICLE - Mahalik, Gautam (2015). Influence of different risk factors on the prevalence of fasciolosis in indigenous cattle reared by the nomads near Bhubaneswar, Odisha. Asian J. Animal Sci., 10(1) : 58-63.

ARTICLE CHRONICLE - Received : 23.03.2015; Revised : 03.05.2015; Accepted : 16.05.2015 